\title{
Editorial: The Global Will (Not) Be Represented
}

\author{
CHARLOTTE CANNING
}

As I read these articles over, I am struck yet again at how many connections I find among them. I have come to think of this issue of Theatre Research International as the unintended special issue. But special issue on what? Overall, I think that taken together the articles are a primer on the challenges, possibilities and imperatives of representing globalization in live performance. But there are other connections as well. The economics and geopolitics of neoliberalism undergird all four explorations, especially as they provoke human migration and upend traditional arts-funding paradigms. What exactly constitutes 'local' is also very much an open question for all the authors. Whether it is because the performances are perceived as 'from here' or 'from away', or because the audiences and the artists do not share a common nation, local is revealed as a very unstable concept.

Importantly, what it means 'to represent' is not taken for granted here. Every meaning of the word - to symbolize, indicate, communicate, depict, serve as or act for slips into the others. Choices made delimit or eliminate others, and when wading into the murky waters of performing globalization, each choice and each exclusion carries an almost unbearable weight for practitioners and audiences alike. But equivocation is not an option for the artists discussed here, and every article allows us to weigh the consequences - intended and unintended - of those choices.

'The Politics and Poetics of Listening: Attending Headphone Verbatim Theatre in Post-Cronulla Australia' begins with the distinction between communication human listening and processing of information - and communications - forms of media, especially social media. The proliferation of public voices has brought about a concomitant diffusion, Caroline Wake argues, a diffusion that undermines our ability to hear what is actually said. This diffusion poses, as she points out, a challenge to practitioners: 'how to intervene in this public sphere without reproducing its structures'. In other words, how do theatre-makers ensure that they are not just adding to the noise? The pioneering work of Anna Deavere Smith, as well as oral-history techniques, offer one solution, which Wakes designates 'ethical eavesdropping'. This mode of production urges spectators to listen with the intent to create change. Hopefully, it makes one's actions more effective by demonstrating how media actually operate and revealing the means of production. Spectators can compare the performed behaviour with their own, and if they do not choose to emulate those new behaviours then at least they can consider the differences between them. The emphasis on listening reorients representation away from replication and toward reflection.

Keren Zaiontz questions representation from a different perspective than does Wake. 'Performing Visions of Governmentality: Care and Capital in 100\% Vancouver' raises the most basic questions about what it means to 'represent' a person, a group 
or a population onstage. The show she discusses performs the relationship between the local and the global, particularly in the context of neoliberal capitalism, with an approach that is supposed to foreground specificity but employs a formula franchised from a theatre company on another continent. What does occur, however, is that the production both intentionally and unintentionally performs the relationship between market representation and artistic representation. Most prominent is the corporate sponsorship of the production, underwritten by a major local bank, in the context of the reduction by the government of its consistent role as an arts funder for the previous fifty years. Despite this neoliberal corporatization of theatre, in terms of funding and even of the playtext itself, Zaiontz documents how the productions's participants bonded and saw themselves as a community, a collective. Through their ongoing interactions, they were drawn to help and support one another in their offstage lives. The possible modes of representation, both onstage and off-, compellingly depict the tensions among the global, local and individual.

'Stages of the Loss, Translation as Contamination: How The Ritual Made It to the Royal National Theatre, London' by Mark O’Thomas documents the struggles the production team experienced bringing a play written by a Brazilian playwright in Portuguese for a British translator (O'Thomas) to render into English for a production premiering on the Royal National Theatre (RNT) stage. These complicated steps (the play was commissioned directly by the RNT) forced the playwright and the translator to confront the conceptual and practical issues of translation and cultural mediation simultaneously. O'Thomas documents how his job was not simply to convert the words from one language to another, but also to figure out how to create a sense of cultural and national context. As he points out, it takes more than words to make a play legible in a language other than its original one. The primary challenge came from the playwright's desire to create a global sense of 'anywhere-ness'. What constituted this in Brazil was not the same as in London if the play was to reach the same audience demographic in both places. The role of the translator shifted in this situation to focus less on words, and more on inventing a globalized context that could be connected to RNT audiences. No longer fully Brazilian, but not fully British, the play gained a new hybridized identity through translation and production.

The problems for representation of migration and the concomitant shifts in what constitutes local and global are taken up by the authors of the final article. In 'ReImagining the Wheel: The Implications of Cultural Diversity for Mainstream Theatre Programming in Australia', Josephine Fleming, Robyn Ewing, Michael Anderson and Helen Klieve focus on audience demographics and ask how representative theatre audiences should be of national or regional populations. Inevitably the question turns on the ways in which the people in the audience do or do not see themselves onstage or in the house. This is particularly significant for populations that have high rates of immigration. Families who do not bring with them practices of attending 'theatre' do not necessarily begin to do so once they settle in their new country. This is true even for those who come from cultures with significant practices of live performance. The article documents the ways in which theatre is not a neutral cultural activity but one specifically dependent on codes and assumptions about family, nationality and aesthetics. 
The act of reading these four articles as a single entity is an excellent way to understand how performance practitioners are addressing the complicated theoretical and political challenges of globalization and neoliberalism. The solutions are provisional and situational, but they do demonstrate a consistent effort on the part of different kinds of performance in varied parts of the world to depict today's struggles in ethical and efficacious ways. No single blueprint emerges here, but new definitions for local, global and migration in the context of neoliberalism are represented imaginatively. Hopefully this issue can inspire all of us to look to our own contexts and create and/or support performance that intervenes strategically in today's complex world.

Fittingly for an issue of TRI that focuses on globalization, representation and translation, I am very happy to announce a new initiative from the International Federation for Theatre Research. TRI will publish translations of recent significant and influential articles of performance scholarship that originally appeared in languages other than English. We ask the proposer to submit a précis of the article and a rationale arguing why it deserves translation and publication and how it serves TRI's mission. The proposal will go through review and, if accepted, the IFTR will underwrite translation costs (up to a designated amount). The translated article will also go through review. For further details please see the IFTR website at www.firt-iftr.org. This is an exciting extension of $T R I$ 's remit to present excellent scholarship on contemporary live performance in all its global contexts. 